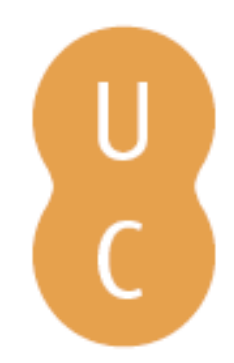

\title{
pommalina
}

\section{A reconstrução do mito de Orfeu no carnaval brasileiro}

\author{
Autor(es): $\quad$ Ribeiro, Ana L. Souza
}

Publicado por: Centro de Estudos Clássicos e Humanísticos da Universidade de

Coimbra; Imprensa da Universidade de Coimbra

URL

persistente: URI:http://hdl.handle.net/10316.2/30277

DOI: $\quad$ DOI:http://dx.doi.org/10.14195/978-989-721-038-9_49

Accessed : $\quad$ 26-Apr-2023 16:14:35

A navegação consulta e descarregamento dos títulos inseridos nas Bibliotecas Digitais UC Digitalis, UC Pombalina e UC Impactum, pressupõem a aceitação plena e sem reservas dos Termos e Condições de Uso destas Bibliotecas Digitais, disponíveis em https://digitalis.uc.pt/pt-pt/termos.

Conforme exposto nos referidos Termos e Condições de Uso, o descarregamento de títulos de acesso restrito requer uma licença válida de autorização devendo o utilizador aceder ao(s) documento(s) a partir de um endereço de IP da instituição detentora da supramencionada licença.

Ao utilizador é apenas permitido o descarregamento para uso pessoal, pelo que o emprego do(s) título(s) descarregado(s) para outro fim, designadamente comercial, carece de autorização do respetivo autor ou editor da obra.

Na medida em que todas as obras da UC Digitalis se encontram protegidas pelo Código do Direito de Autor e Direitos Conexos e demais legislação aplicável, toda a cópia, parcial ou total, deste documento, nos casos em que é legalmente admitida, deverá conter ou fazer-se acompanhar por este aviso.

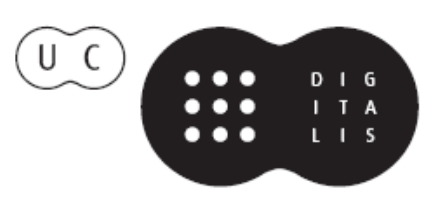




\section{De ayer a hoy}

\section{Influencias clásicas en la literatura}

\section{Aurora López, Andrés Pociña, Maria de Fátima Silva (coords.)}




\title{
A reconstrução do mito de Orfeu no Carnaval Brasileiro
}

\author{
Ana L. Souza Ribeiro \\ Universidade Federal de Minas Gerais
}

\begin{abstract}
No presente trabalho, pretende-se analisar como o mito de Orfeu, contado na obra Geórgicas de Virgílio, aparece, de maneira palimpséstica, na peça Orfeu da Conceição, de Vinícius de Moraes, produzida no Brasil do século XX. Serão feitas algumas considerações sobre as escolhas do autor brasileiro de forma a justificá-las e relacioná-las ao mito em questão. Pretende-se, então, mostrar como, na obra contemporânea, misturam-se símbolos que retomam a literatura clássica com signos que remetem à cultura e tradição brasileira. A partir desta releitura, na combinação do mito com a festa profana, pagã e popular que é o carnaval, evidencia a mistura das duas culturas no costume e tradição brasileiros.
\end{abstract}

Assim é que, quando ao reler numa velha mitologia o mito grego de Orfeu, o divino músico da Trácia, nele senti a estrutura de uma tragédia negra carioca.

Vinícius de Moraes

Este trabalho consiste em analisar a retomada da literatura clássica representada pelo mito de Orfeu na obra Geórgicas, de Virgílio, na peça Orfeu da Conceição, de Vinícius de Moraes, produzida no Brasil do século XX.

A peça foi produzida em setembro1956 no Teatro Municipal do Rio de Janeiro por Leo Jusi. O elenco foi composto por atores do Teatro Experimental do Negro e participações de Tom Jobim, um famoso compositor, maestro, pianista, cantor. É considerado um dos maiores expoentes da música brasileira e um dos criadores do movimento da bossa nova; foi responsável por musicar e orquestrar a peça. E Oscar Niemeyer, um arquiteto brasileiro, considerado um dos nomes mais influentes na arquitetura moderna internacional, famoso pela construção de Brasília, incumbido do cenário. Embora tenha permanecido somente dez dias em cartaz, a peça foi bem aceita pela crítica na época e, nos dias atuais, é considerada um passo à modernidade musical e teatral brasileira. A apresentação do mito de Orfeu na América mostra - aqui cito Cacá Diegues, cineasta brasileiro - que a ideia de transpor o mito do poeta e músico grego para uma favela carioca nasceu de uma conversa de Vinícius de Moraes com o escritor americano Waldo Frank sobre a Grécia e os negros brasileiros, quando este visitou o Rio de Janeiro no início de 1942. Vinícius, posteriormente, ao reler o mito de Orfeu, na casa do arquiteto Carlos Leão, traçou as linhas gerais da peça, cujo título lhe havia sido sugerido por João Cabral de Melo Neto, um poeta e diplomata brasileiro. Os três atos foram desenvolvidos no Brasil e nos EUA, durante o período em que Vinícius serviu no consulado do Brasil em 
Los Angeles, e arrematados em Paris, em outra missão diplomática no âmbito desse movimento de reflexão e de produção direcionada a manifestações artísticas, culturais e sociais de grupos até então relegados, por meio de um cruzamento de matrizes culturais africanas e greco-romanas (européias).

No texto publicado no programa de Orfeu da Conceição em 1956, Vinícius nos diz em entrevista:

Foi-me fácil escrever, nessa mesma noite, de um só fôlego, todo o primeiro ato da peça, transpondo diretamente o mito grego para o morro carioca. Tudo o que fiz foi colocar nas mãos de um herói de favela, em lugar da lira helênica, o violão brasileiro, e submetê-lo ao sublime e trágico destino de seu homônimo grego - destino que o levou, através da integração total pela música, ao conhecimento do amor no seu mais alto e belo sentido e, pelo amor, às forças incontroláveis da paixão, à destruição eventual da harmonia em si mesmo e no mundo em torno e, finalmente, à sua própria morte (Moraes, p. 37).

Vinícius de Moraes recria o mito nos cenários, levando as figuras mitológicas para o carnaval no Rio de Janeiro, lugar e festa com grande representatividade cultural para o Brasil. $\mathrm{O}$ primeiro ato compreende a formulação das personagens centrais, a sua posição no espaço e tempo, e posteriormente utiliza do embasamento da tragédia, sob perspectivas do destino, tal como deverá o processo de atuação.

O herói Orfeu, que no mito é cantor, músico e poeta de procedência trácia que, com seu canto, acalmava homens, domava feras e comovia até as pedras, na obra supracitada possui o mesmo caráter simbólico e metafórico: o personagem principal, também de nome Orfeu, é reproduzido negro (o negro que tem uma cultura e temperamento específico, e embora interligado no contexto racial brasileiro, sempre manifestou a necessidade de prosseguir na sua própria cultura, proporcionando, deste modo, uma contribuição realmente particular à cultura brasileira, aquela que livra dos preconceitos de cor, credo e classe), boêmio, compositor de sambas, que vive o prazer de cada instante. Mora na favela, particularidade e espaço importante na caracterização nacional e representação do povo brasileiro. Ao invés de uma lira, comum e popular na Antiguidade Clássica, Orfeu toca violão, instrumento que tem as mesmas características no Brasil contemporâneo. Assim como o personagem mítico, deixa em estado de êxtase o morro e o pacifica, causando amor e concórdia. Por causa disso, recebe o sobrenome "de Conceição", o que representa, no Brasil, as pessoas humildes e sem procedência definida. Como no mito, suas canções têm um poder sobrenatural sobre as pessoas É Orfeu que apresenta ao mundo a semente da beleza, que o torna cheio de canto, de poesia e de doçura. 
Em Orfeu da Conceição, o violão pode fazer milagres, é como parte de Orfeu. $\mathrm{Na}$ abertura ele toca em solo a valsa Eurídice, tema romântico da peça, composta por Antônio Carlos Jobim, o mesmo que musicou e orquestrou a peça, e no decorrer do teatro, sola também as introduções dos sambas e os tristes acordes com que Orfeu procura traduzir o sofrimento e os conflitos que lhe saem do interior. $\mathrm{O}$ samba é representado mimeticamente em um aspecto que ilumina o mito de Orfeu.

No livro Platão e o orfismo, Bernabé cita que, na República de Platão, Orfeu aparece como um poeta. Ainda, segundo Bernabé:

A tradição, ademais, atribuía à habilidade musical de Orfeu qualidades sobrehumanas. Era proverbial, desde os primeiros testemunhos, a fascinação que Orfeu exercia sobre os que o ouviam. Platão se refere a esta qualidade em uma referência, mesmo irônica, no Protágoras, na qual compara os discípulos dos sofistas com os seres fascinados pelo canto do citarista trácio: "muitos me pareceram estrangeiros, os que acompanham Protágoras por todas as cidades que passa, encantando-os com a sua voz como Orfeu, e que seguem, fascinados, a sua voz" ${ }^{1}$.

Eurídice, a ninfa mitológica, é eternizada por Vinícius quando este corporifica na sensualidade da mulata brasileira, segundo um valor adquirido e vinculado, desde o Brasil colônia. Sua representação destoa um pouco do mito porque, apesar de encantar Orfeu, é casada com Aristeu. Porém, o fato de ser casada não impede o amor dos dois, que acabam encontrando-se secretamente. $\mathrm{Na}$ mitologia grega Eurídice, quando perseguida por Aristeu, é picada por uma cobra, já na peça em questão, a personagem é assassinada pelo ciumento marido, que acaba ferindo-a com um punhal.

No segundo ato da peça, Orfeu, na louca procura de Eurídice, vai a um clube carnavalesco denominado "Os maiorais do inferno", onde os personagens festejavam o baile, que é presidido por Prosérpina e Plutão, fazendo alusão à sua ida ao mundo inferior, governado por Plutão e Perséfone. Nesta parte da adaptação do mito, Vinícius de Moraes apresenta o cão Cérbero como Leão de Chácara - nome conhecido popularmente, em algumas regiões do Brasil, como vigilante, segurança em festas ou bailes - e o mesmo tenta interromper a entrada de Orfeu, mas acaba sendo persuadido pela música de seu violão, assim como no mito apresentado por Virgílio. Após sua entrada na festa de carnaval, o personagem Orfeu diz:

Onde estou eu? Quem sou eu? Que é que vim fazer aqui? Como é que foi? Isso é o inferno e eu quero o céu! Eu quero a minha Eurídice! Minha mulata linda, coberta de sangue..." (Moraes, p. 60, 1956).

\footnotetext{
${ }^{1}$ Pl. Prot. 315a (OF 949 I) [T 6].
} 
Após todas as indagações, ele procura por seu grande amor, mas não a encontra, e acaba por se embriagar.

Uma questão importante que a peça trata de forma a destoar do mito é não relatar uma Eurídice perdida, justamente pela possibilidade de estar ela presente em todas as mulheres. Fato mostrado na peça com as dançarinas da gafieira que corporificam Eurídice, de forma simbólica apenas. A loucura de Orfeu da Conceição transforma cada mulher, que dança, na amada.

Ponto importante na obra de Vinícius, em que se aproxima da lenda, é quando a Dama Negra fala a Orfeu com a voz de Eurídice - no caso, um apelo à morte para que o músico entrasse em seus domínios. Assim, Eurídice assimila-se à morte, que é a única morada onde se pode alcançar o amor despido do efêmero terrestre.

Orfeu na peça é receptivo a todas as mulheres, e em certo momento encontra-se com Mira, que sua foi pretendida, mas desprezada. Enfurecida com o abandono, Mira influencia outras mulheres e atiram em Orfeu facas e navalhas, provocando sua morte e jogando seu violão do alto do morro. Tal fato em Virgílio acontece pelas mãos das bacantes que destroem sua lira e o decepam. Entretanto sua cabeça vaga pelo rio cantando e dizendo profecias.

A combinação do mito com a festa profana, pagã e popular que é o carnaval evidencia a mistura das duas culturas no costume e tradição brasileiros. $\mathrm{O}$ festejo misturado à música e ao encantamento de Orfeu oferece uma nova paisagem para a materialização do mito, renovando-o. O poder da música, porém, tanto na Antiguidade quanto no novo contexto em que o mito é apresentado, não é o suficiente para salvar Orfeu do amor que o aprisionou e causou sua desgraça.

O mito de Orfeu reúne os grandes temas poéticos da obra de Vinícius: a união entre a música e a poesia, a apresentação marcante da mulher, a obsessão pela morte e a fé no amor absoluto.

$\mathrm{Na}$ obra teatral, o autor se deixou seduzir pelo gosto de uma poesia fácil, que aos versos apresenta um tom bem popular. Segundo Coelho, "como a peça de Vinícius, esta obra transportava para o Brasil o mito grego". (Coelho, p. 231, 2008).

De acordo com Coelho:

busco mostrar a importância de conhecermos estas versões, para entendermos melhor as adaptações do mito na sociedade brasileira: Orfeu (1999), de Carlos Diegues, e Orfeu do carnaval (1958), de Marcel Camus, ambas baseadas na peça Orfeu da Conceição (1956), de Vinícius de Moraes. Esta comparação pode permitir-nos ainda observar os significados de alterações na assimilação da tradição clássica greco-romana pela literatura e cinema americanos, a partir das especificidades do seu contexto histórico (Coelho, p .222, 2008). 


\section{Bibliografia}

Moraes, Vinícius de, Orfeu da Conceição, São José, Rio de Janeiro, 1960.

Coelho, Maria Cecília Nogueira, Entre a bistória e o mito: Orfeu na América, segundo Sidney Lumet, ArtCultura, Uberlândia, v. 10, n. 17, pp. 221235, jul.-dez. 2008.

Virgílio, Geórgicas, Trad.: Antônio Feliciano de Castilho e Manuel Odorico Mendes, Ed. Brasileira, São Paulo, 1970.

Magaldi, Sábato, Moderna dramaturgia brasileira, Ed. Perspectiva, São Paulo, 2008.

Bernabé, Alberto, Platão e o orfismo: diálogos entre religião e filosofia, Trad. Dennys Garcia Xavier, Ed. Annablume, São Paulo, 2011. 